\title{
ANALISIS SWOT, BISNIS MODEL KANVAS, DAN KELAYAKAN KEUANGAN STUDI KASUS BISNIS AMIGURUMI M's CROCHET
}

\author{
Francisca Hermawan \\ Petrus Pius Salamin \\ Meiliana \\ Unika Atma Jaya Jakarta \\ Francisca.h@atmajaya.c.id
}

\begin{abstract}
Amigurumi M's Crochet's business is a craft category in the creative industry. Strength M's Crochet is divided into 3 competencies, core competencies, and resources, while threats emerge from old competitors and products are easy to replicate. The value offered M's Crochet is to sell quality amigurumi, timely delivery and products can be tailored to the wishes of consumers. The target market of M's Crochet is upper middle class society, aged $3^{+}$years, and has an artistic soul. To maintain customer relationships, M's Crochet uses social media (Line, Instagram, Tokopedia, Website, and Email) for product promotion. M's Crochet sales growth increaset 3.1 percent per year assumed to be equal to the growth of the creative industri. Based on the financial feasibility calculation, the NPV earned amounted to Rp4.113.019.207.00 indicating that M's Crochet business is feasible to run. Payback period of initial investment for 3.5 months.
\end{abstract}

Keywords : amigurumi, M's Crochet, boneka rajutan.

\section{PENDAHULUAN}

Dalam berita yang dilansir dari Antara News (2013), Asosiasi Pengusaha Mainan Indonesia memprediksi bahwa total kebutuhan boneka di Indonesia mencapai rata-rata 375 juta per tahun, belum termasuk produk yang dipesan untuk souvenir/promosi. Oleh karena itu, di dalam negeri membutuhkan setidaknya 2.000 pelaku Industri Kecil Menengah (IKM) bidang manufaktur boneka agar bisa memenuhi kebutuhan boneka dalam negeri. Amigurumi sebagai bagian dari industri boneka sehingga saya perkirakan juga memiliki peluang pasar yang sama seperti industri boneka.

M's Crochet merupakan sebuah bisnis yang berbentuk perseorangan yang bergerak di bidang kerajinan, yaitu boneka rajutan (amigurumi). Amigurumi adalah sebuah karya seni merajut atau boneka rajut yang berbentuk hewan-hewan lucu atau makhluk antropomorfik. Pembuatan produk amigurumi menggunakan benang katun asli yang tidak berbahaya sehingga aman digunakan oleh konsumen. Produk M's Crochet ditujukan untuk masyarakat dari segala umur dan gender yang menyukai kesenian dan memiliki rasa peka terhadap keindahan (estetika). Amigurumi yang dihasilkan memiliki nilai yang lebih tinggi dibandingkan dengan produk sejenis karena dibuat menggunakan tangan oleh tenaga ahli yang terampil dalam merajut sehingga lebih tahan lama, bersifat unik, serta trendi. Kualitas yang diberikan M's Crochet dimulai dari pemilihan bahan baku, proses produksi yang juga 
melalui proses pengecekkan produk, pengemasan produk, hingga proses pendistrubusian langsung maupun tidak langsung kepada konsumen akhir.

\section{Perkembangan Industri Kreatif}

Pertumbuhan industri kreatif di Indonesia cukup pesat. Berdasarkan data dari Badan Pusat Statistik (BPS), rata-rata kenaikan pertumbuhan industri kreatif selama 5 dari tahun 2006-2010 sebesar 3,1 persen. Hal ini juga dipengaruhi oleh ekspor dan impor produk kerajinan tangan Indonesia kepada negara-negara tetangga.

\section{Tabel 1}

Indikator Industri Kreatif

\begin{tabular}{|l|c|c|c|c|c|c|}
\hline INDIKATOR & $\mathbf{2 0 0 6}$ & $\mathbf{2 0 0 7}$ & $\mathbf{2 0 0 8}$ & $\mathbf{2 0 0 9}$ & $\mathbf{2 0 1 0}$ & $\begin{array}{c}\text { Rata- } \\
\text { rata 5 } \\
\text { tahun }\end{array}$ \\
\hline $\begin{array}{l}\text { Pertumbuhan } \\
\text { Industri Kreatif }\end{array}$ & $4,95 \%$ & $2,73 \%$ & $-0,50 \%$ & $2,27 \%$ & $6,03 \%$ & $3,10 \%$ \\
\hline $\begin{array}{l}\text { Kontribusi } \\
\text { Ekonomi } \\
\text { Nasional }\end{array}$ & $7,69 \%$ & $7,42 \%$ & $6,97 \%$ & $7,03 \%$ & $7,29 \%$ & $7,28 \%$ \\
\hline $\begin{array}{l}\text { Jumlah Tenaga } \\
\text { Kerja (juta } \\
\text { orang) }\end{array}$ & 7,009 & 7,375 & 7,624 & 8,207 & 8,553 & 7,75 \\
\hline $\begin{array}{l}\text { Partisipasi } \\
\text { Tenaga Kerja } \\
\text { Nasional }\end{array}$ & $7,34 \%$ & $7,38 \%$ & $7,43 \%$ & $7,83 \%$ & $7,90 \%$ & $7,58 \%$ \\
\hline $\begin{array}{l}\text { Jumlah } \\
\text { Perusahaan (juta } \\
\text { perusahaan) }\end{array}$ & 2,576 & 2,835 & 3,035 & 3,225 & 2,35 & 3 \\
\hline $\begin{array}{l}\text { Nilai Ekspor } \\
\text { Industri Kreatif } \\
\text { (juta rupiah) }\end{array}$ & 84.840 & 95.209 & 114.925 & 116.651 & 131.251 & 108.575 \\
\hline $\begin{array}{l}\text { Kontribusi } \\
\text { Ekspor Industri } \\
\text { Kreatif }\end{array}$ & $9,33 \%$ & $8,86 \%$ & $7,52 \%$ & $10,65 \%$ & $9,25 \%$ & $9,12 \%$ \\
\hline $\begin{array}{l}\text { Nilai Impor } \\
\text { Industri Kreatif } \\
\text { (juta rupiah) }\end{array}$ & 6.045 & 8.077 & 10.442 & 15.491 & 16.262 & 11.263 \\
\hline $\begin{array}{l}\text { Kontribusi Impor } \\
\text { Industri Kreatif }\end{array}$ & $1,10 \%$ & $1,15 \%$ & $0,82 \%$ & $1,70 \%$ & $1,33 \%$ & $1,22 \%$ \\
\hline $\begin{array}{l}\text { Net Trade (juta } \\
\text { rupiah) }\end{array}$ & 78.795 & 87.131 & 104.483 & 101.161 & 144.989 & 97.312 \\
\hline
\end{tabular}

\section{REVIEW LITERATUR DAN HIPOTESIS}

\section{SWOT}

Analisis SWOT merupakan suatu bentuk analisis yang digunakan oleh manajemen perusahaan atau organisasi yang sistematis dan dapat membantu dalam usaha penyusunan suatu rencana yang matang untuk mencapai tujuan perusahaan atau organisasi tersebut. Dan analisis SWOT merupakan suatu bentuk analisis situasi dan kondisi yang bersifat deskriptif (memberi suatu gambaran) tentang sebuah perusahaan atau organisasi.

\section{Manfaat Analisis SWOT}

Analisis SWOT dapat digunakan untuk membantu melihat sisi - sisi yang terabaikan atau tidak terlihat dari sebuah perusahaan atau organisasi. Dan analisis ini juga merupakan bentuk instrumen yang bermanfaat dalam melakukan analisis strategis dalam manajemen perusahaan atau organisasi.

\section{BMK}

Salah satu perangkat analisis yang bisa membantu kita menemukan model bisnis yang tepat adalah model bisnis kanvas. Menurut Alexander Osterwalder mencoba menjelaskan sebuah framework sederhana untuk mempresentasikan elemen - elemen penting yang terdapat dalam sebuah model bisnis.

Sembilan elemen penting yang mendukung kemajuan bisnis adalah:

\section{Customer Segments.}

Elemen pertama menentukan segmen pelanggan mana yang akan menjadi target bisnis kita.

\section{Value Propositions.}

Membahas mengenai manfaat atau benefit apa yang akan didapatkan para pelanggan. Hal ini menjadi kesempatan untuk menjabarkan kekuatan dan keunggulan yang membedakan bisnis yang dijalankan dengan bisnis yang lain.

\section{Channels.}

Melalui penggunaan channels yang tepat, maka value propositions dapat disampaikan kepada customer customer segments.

\section{Revenue Streams.}

Elemen ini harus dikelola semaksimal mungkin untuk meningkatkan pendapatan bisnis. 


\section{Custmoer Relationships.}

Membahas tentang jalinan hubungan kita dengan pelanggan. Perlu pengawasan yang ketat dan insentif agar pelanggan bisnis tidak mudah berpaling ke bisnis yang lain hanya karena jalinan hubungan yang kurang baik.

6. Key Activities.

Kegiatan yang harus dilakukan untuk menciptakan value propositions yang efektif.

\section{Key Resources.}

Semua jenis sumber daya mulai dari pengelolaan bahan baku, penataan SDM dan penataan proses operasional menjadi perhatian dalam membuat model bisnis.

\section{Key Partnership.}

Menjaga hubungan baik dengan para supplier atau tim pemasaran harus diperhatikan.

\section{Cost Structure.}

Mengelola biaya secara efisien akan membuat bisnis yang dijalankan menjadi lebih hemat dan bisa meminimalkan risiko kerugian.

\section{Strategi Bisnis}

Pertumbuhan bisnis M's Crochet setiap tahunnya didasarkan pada rata-rata pertumbuhan industri kreatif selama 5 tahun sebesar 3,10 persen. M's Crochet akan menyesuaikan produk amigurumi dengan keinginan konsumen. $M$ 's Crochet selalu mengutamakan kualitas dan nilai produk yang diberikan kepada konsumen. Oleh karena itu, M's Crochet menjaga kualitas produk yang dimulai dari pemilihan bahan baku, proses produksi yang juga melalui proses pengecekkan produk, pengemasan produk, hingga proses pendistrubusian langsung maupun tidak langsung kepada konsumen akhir

\section{Visi dan Misi M's Crochet}

\section{Visi:}

Menjadi produsen amigurumi berkualitas dan berkredibilitas di DKI Jakarta sekitar.
Misi:

- Menghasilkan produk berkualitas yang dimulai dari pemilihan bahan baku hingga produk sampai ke tangan konsumen.

- Menyediakan produk yang memiliki variasi bentuk dan warna untuk memenuhi selera konsumen.

- Mengembangkan pasar, dan memperluas pendistribusian melalui toko-toko retailer, agar menjangkau komitmen sebesar mungkin.

M's Crochet melakukan segmentasi pasar dan menggolongkannya ke dalam 3 variabel segmentasi sebagai berikut :

a. Segmentasi Geografis

Amigurumi M's Crochet menetapkan segmentasi berdasarkan geografis yaitu kompleks perumahan kelas atas di DKI Jakarta yang merupakan kota metropolitan dengan mobilitas tinggi. DKI Jakarta memiliki 5 kota administrasi yaitu Jakarta Utara, Jakarta Pusat, Jakarta Selatan, Jakarta Timur, dan Jakarta Barat.

b. Segmentasi Demografi

Amigurumi M's Crochet menentukan segmentasi demografi berdasarkan jenis kelamin yaitu untuk perempuan untuk usia 3 tahun ke atas.

c. Segmentasi Psikografis

Amigurumi M's Crochet menetapkan segmentasi psikografis yaitu konsumen yang memiliki jiwa seni atau artistik dan rasa peka terhadap keindahan (estetika).

Amigurumi M's Crochet memposisikan diri dalam benak konsumen sebagai produsen boneka rajutan (amigurumi) yang memiliki kegunaan sebagai gantungan tas, kunci, dan HP; hiasan mobil; pajangan di rumah maupun meja kantor/belajar; maupun sebagai mainan anakanak, serta memiliki kualitas terbaik dengan mengikuti gaya hidup masyarakat di kota DKI Jakarta dan memiliki siklus hidup produk yang tahan lama. 


\section{Model Bisnis Kanvas}

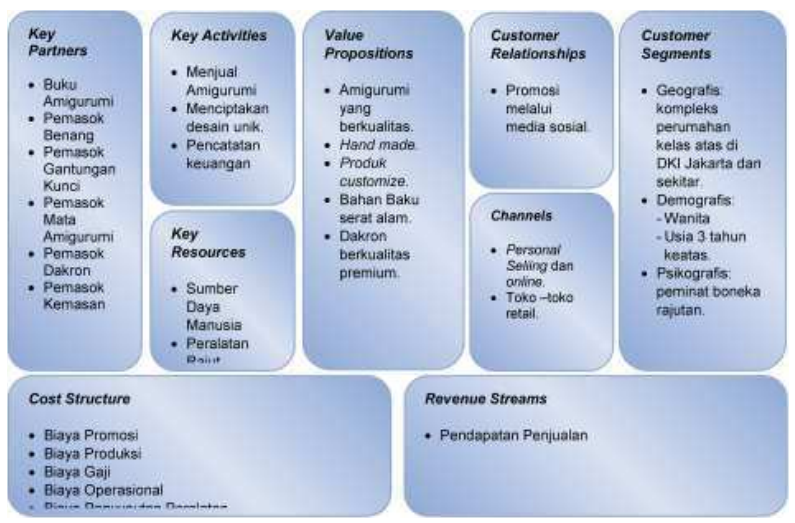

Gambar 1

\section{Model Bisnis Kanvas M's Crochet}

Model bisnis kanvas M's Crochet:

\section{Customers Segment}

M's Crochet melakukan segmentasi pelanggan berdasarkan geografiis, demografis, dan psikografis.

a) Segmentasi Geografis ialah kompleks perumahan kelas atas di daerah DKI Jakarta dan sekitar. DKI Jakarta memiliki 5 kota administrasi yaitu Jakarta Utara, Jakarta Pusat, Jakarta Selatan, Jakarta Timur, dan Jakarta Barat.

b) Segmentasi Demografis ialah wanita yang berusia 3 tahun ke atas.

c) Segmentasi Psikografis ialah peminat boneka rajutan.

\section{Value Propositions}

M's Crochet menawarkan produk gantungan, hiasan/pajangan serta mainan anakanak yang berkualitas serta proses pengiriman yang sampai ke tangan konsumen tepat waktu. Selain itu, produk $M$ 's Crochet merupakan produk hand made (buatan tangan) sehingga memiliki nilai lebih dibandingkan dengan produk manufakur (pabrik). Kami juga melayani produk custom sehingga bisa disesuaikan dengan keinginan konsumen dan perubahan tren yang terjadi di masyarakat. M's Crochet juga menggunakan bahan yang berasal dari serat alam serta menggunakan dakron dengan kualitas premium.

\section{Channels}

M's Crochet akan menggunakan media sosial, mengikuti pameran-pameran, serta melalui toko-toko retail yang sering dikunjungi sebagai saluran untuk menjual produk kepada masyarakat. Penggunaan media sosial dapat mempercepat pengenalan produk karena tingginya penggunaan internet dan smartphone di Indonesia. Penjualan juga akan dilakukan secara personal selling dengan mengikuti pameran-pameran yang diadakan secara sementara sehingga konsumen dapat mengetahui informasi lebih detail mengenai produk yang ditawarkan. Konsumen juga dapat mendapati produk amigurumi $M$ 's Crochet di toko-toko retail.

\section{Revenue Stream}

Sumber pendapatan $M$ 's Crochet seratus persen berasal dari pelanggan yang membeli produk M's Crochet melalui online, maupun offline.

\section{Customers Relationship}

M's Crochet menjalin dan menjaga hubungan dengan pelanggan melalui media sosial, yaitu Instagram, Line, Email, Whatsapp, dan Tokopedia. Melalui Instagram, Line, dan Tokopedia, M's Crochet dapat menampilkan fotofoto varian warna produk serta model produk terbaru. Sedangkan melalui media sosial Line, Whatsapp, dan Email berguna untuk menerima pesanan pelanggan dan memberitahukan para pelanggan mengenai promosi produk.

6. Key Activities

Aktivitas kunci dalam memenuhi target penjualan M's Crochet ialah menjual produk amigurumi itu sendiri. M's Crochet menjual 
Analisis SWOT, Bisnis Model Kanvas, Dan Kelayakan Keuangan Studi Kasus Bisnis Amigurumi M's Crochet

produk amigurumi dengan menawarkan berbagai varian warna dan juga bentuk agar konsumen dapat memilih gantungan, hiasan/pajangan serta mainan sesuai dengan keinginan konsumen. $M$ 's Crochet juga akan melakukan pancatatan laporan keuangan yang akan digunakan sebagai acuan dalam setiap mengambil keputusan bisnis.

\section{Key Resources}

Yang menjadi sumber daya penting/ utama dalam membuat bisnis ini menjadi sukses adalah orang-orang yang berada dalam organisasi ini (sumber daya manusia). M's Crochet memilih sumber daya dengan selektif sehingga sesuai dengan kebutuhan organisasi agar terciptanya proposisi nilai. Sumber daya manusia yang dibutuhkan adalah pengrajin yang kreatif, pemasaran, dan keuangan. Selain itu, sumber daya lainnya juga tidak kalah penting untuk menjaga kualitas produk yang sudah dijanjikan kepada konsumen, yaitu peralatan rajut yang terjaga kebersihannya.

\section{Key Partnerships}

Kemintraan M's Crochet yang menjadi penting dalam bisnis amigurumi ini adalah buku amigurumi, pemasok benang, pemasok gantungan kunci, pemasok mata amigurumi, pemasok dakron dan pemasok kemasan produk. Jika salah satu mitra tidak ada, maka bisnis ini tidak dapat berjalan dengan baik.

\section{Cost Structure}

Besarnya biaya yang ditanggung $M$ 's Crochet, digunakan untuk memproduksi produk amigurumi. Selain itu, biaya operasional meliputi biaya promosi, biaya produksi, biaya gaji karyawan, biaya stand, biaya endorsement, biaya sewa rumah, dan biaya penyusutan peralatan. Tingginya biaya yang dimiliki usaha ini menyebabkan M's Crochet harus meningkatkan penjualan sebesar-besarnya untuk menutupi semua biaya.

\section{SWOT M's Crochet}

Tabel 2

\begin{tabular}{|c|c|c|}
\hline EFAS & $\begin{array}{l}\text { Strengths (S): } \\
\text { 1. Produk amigurumi } \\
\text { yang disesuaikan } \\
\text { dengan keinginan } \\
\text { konsumen. } \\
\text { 2. Pengiriman tepat } \\
\text { waktu. } \\
\text { 3. Memiliki modal } \\
\text { yang cukup. } \\
\text { 4. Menggunakan } \\
\text { bahan baku benang } \\
\text { katun asli. } \\
\text { 5. Tenaga kerja yang } \\
\text { ahli merajut. }\end{array}$ & $\begin{array}{l}\text { Weaknesses (W): } \\
\text { 1. Bisnis masih } \\
\text { baru sehingga } \\
\text { belum dikenal } \\
\text { oleh masyarakat. } \\
\text { 2. Pengetahuan } \\
\text { dalam } \\
\text { menjalankan } \\
\text { bisnis yang } \\
\text { masih sedikit. } \\
\text { 3. Pembuatan } \\
\text { produk yang } \\
\text { membutuhkan } \\
\text { waktu lebih } \\
\text { lama. }\end{array}$ \\
\hline $\begin{array}{l}\text { Opportunities (O): } \\
\text { 1. Sedikitnya } \\
\text { penjual produk } \\
\text { amigurumi. } \\
\text { 2. Banyak orang } \\
\text { yang menyukai } \\
\text { barang-barang } \\
\text { lucu dan } \\
\text { mengandung nilai } \\
\text { seni. } \\
\text { 3. Produksi boneka } \\
\text { di Indonesia masih } \\
\text { belum memenuhi } \\
\text { kebutuhan } \\
\text { masyarakat dalam } \\
\text { negeri. }\end{array}$ & $\begin{array}{l}\text { Strategi SO: } \\
\text { (strategi yang } \\
\text { menggunakan } \\
\text { kekuatan untuk } \\
\text { memanfaatkan } \\
\text { peluang) } \\
\text { 1. Meningkatkan } \\
\quad \text { kuantitas produksi } \\
\text { amigurumi yang } \\
\quad \text { disesuaikan } \\
\text { dengan keinginan } \\
\text { konsumen. } \\
\text { 2. Menciptakan produk } \\
\text { dengan tekstur yang } \\
\text { disesuaikan dengan } \\
\text { jenis produk. }\end{array}$ & $\begin{array}{l}\text { Strategi WO: } \\
\text { (strategi yang } \\
\text { meminimalkan } \\
\text { kelemahan untuk } \\
\text { memanfaatkan } \\
\text { peluang) } \\
\text { 1. Gencar dalam } \\
\text { menjual produk } \\
\text { amigurumi. } \\
\text { 2. Memperbanyak } \\
\text { SDM yang } \\
\text { demi memenuhi } \\
\text { kebutuhan } \\
\text { boneka dalam } \\
\text { bentuk rajutan. }\end{array}$ \\
\hline $\begin{array}{l}\text { Threats }(\mathbf{T}) \text { : } \\
\text { 1. Pesaing lama } \\
\text { yang menawarkan } \\
\text { produk sejenis. } \\
\text { 2. Produk mudah } \\
\text { ditiru. }\end{array}$ & $\begin{array}{l}\text { Strategi ST: } \\
\text { (strategi yang } \\
\text { menggunakan } \\
\text { kekuatan untuk } \\
\text { mengatasi ancaman) } \\
\text { 1. Meninimalkan biaya } \\
\text { yang dikeluarkan } \\
\text { agar harga produk } \\
\text { mampu bersaing di } \\
\text { pasar. } \\
\text { 2. Menambah } \\
\text { peralatan merajut } \\
\text { yang dibutuhkan. } \\
\text { 3. Memperluas } \\
\text { jenis bahan yang } \\
\text { digunakan dan jenis } \\
\text { rajutan yang dijual. }\end{array}$ & $\begin{array}{l}\text { Strategi WT: } \\
\text { (strategi yang } \\
\text { meminimalkan } \\
\text { kelemahan untuk } \\
\text { menghindari } \\
\text { ancaman) } \\
\text { 1. Secara terus } \\
\text { menerus } \\
\text { melakukan } \\
\text { pemasaran dan } \\
\text { promosi agar } \\
\text { produk dikenal } \\
\text { masyarakat. } \\
\text { 2. Meningkatkan } \\
\text { jumlah SDM } \\
\text { yang terampil } \\
\text { agar tercipta } \\
\text { kualitas yang } \\
\text { diinginkan } \\
\text { konsumen dan } \\
\text { meningkatkan } \\
\text { kuantitas } \\
\text { produksi. }\end{array}$ \\
\hline
\end{tabular}




\section{Manajemen Sumber Daya Manusia M's Crochet}

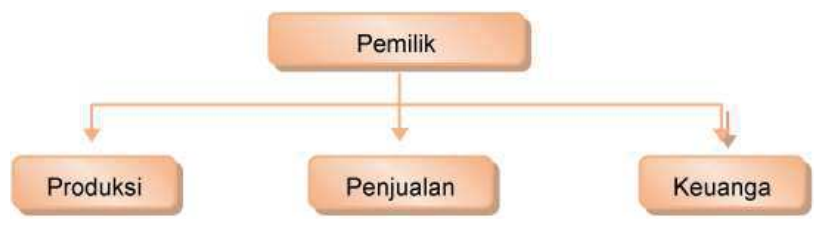

1. Pemilik

Penulis atau pemilik merupakan bagian kepala dari tubuh organisasi M's Crochet sehingga kehadiran pemilik sangat penting dalam jalannya sebuah organisasi. Pemilik bertanggungjawab untuk menentukan visi, misi, dan tujuan jangka panjang serta menyampaikannya kepada karyawan. Pemilik juga memiliki kewajiban untuk melakukan perencanaan strategi jangka pendek dan jangka panjang untuk memastikan bisnis dapat berjalan dengan baik. Jabatan sebagai pemilik tidak lepas dari tindakan memimpin dalam mengambil keputusan, mengawasi, mengatur, dan membantu jalannya operasi bisnis. Karyawan juga memiliki andil dalam mengambil keputusan yang kemudian akan didiskusikan dengan pemilik. Tidak berhenti dengan deskripsi pekerjaan di atas, pemilik juga harus bisa memotivasi karyawan-karyawannya agar dapat memberikan performa terbaik. Selain itu, pemilik juga harus mencari dan memesan bahan baku yang hendak dibeli serta mengontrol bahan baku tersebut.

Pemilik merangkap sebagai bagian keuangan dimana deskripsi pekerjaan di bagian ini adalah menentukan target keuangan yang harus dicapai, melakukan pencatatan penjualan barang, merekap bukti pembelian bahan baku, serta melakukan konfirmasi penerimaan uang yang ditransfer maupun secara tunai. Selain itu, pemilik wajib melakukan pencatatan keuangan perusahaan secara teratur dan membuat laporan keuangan setiap bulannya. Pemilik juga akan merangkap sebagai bagian penjualan dan produksi jika diperlukan.

\section{Produksi}

Bagian produksi bertugas untuk membuat produk amigurumi yang bervariasi dari segi bentuk dan warna untuk dijual kepada konsumen, serta menciptakan ide baru dari bentuk amigurumi yang di produksi. Bagian produksi bertanggung jawab untuk meningkatkan jumlah produksi. Selain membuat amigurumi, bagian produksi juga bertugas untuk melakukan pengemasan terhadap produk sudah jadi. Bagian produksi juga bertanggung jawab untuk quality control untuk setiap produk yang diproduksi dan melakukan kontrol atas persediaan bahan baku dan memberikan laporan kepada pemilik.

\section{Penjualan}

Bagian penjualan bertanggung jawab untuk memasarkan $M$ 's Crochet agar dikenal oleh masyarakat dan menjual produk-produk yang sudah di produksi, serta menerima dan melayani pelanggan baik secara langsung maupun tidak langsung. Jika pesanan secara online, maka bagian penjualan harus mengantarkan produk ke jasa pengiriman agar dapat dilakukan proses pengiriman kepada konsumen (seperti JNE, Sicepat, ataupun Go-send). Bagian penjualan juga bertugas untuk membantu bagian produksi dalam proses pembuatan amigurumi apabila dibutuhkan dan juga melakukan pengecekan terhadap persediaan produk jadi.

\section{METODE PENELITIAN}

Metode penelitian yang digunakan M's Crochet adalah studi dokumentasi yang menggunakan data sekunder. Data sekunder yang digunakan adalah SWOT, Bisnis Model Kanvas, dan Kelayakan Keuangan yang terdiri dari perhitungan NPV, dan Payback Period. 


\section{HASIL PENELITIAN DAN PEMBAHASAN}

\section{KEUANGAN M's CROCHET}

Tabel 4. Target Penjualan M's Crochet 2018

\begin{tabular}{|c|c|c|c|c|c|c|}
\hline & $\begin{array}{l}\text { Hari } \\
\text { Kerja } \\
\text { (hari) }\end{array}$ & $\begin{array}{c}\text { Jumlah } \\
\text { Penjulan } \\
\text { per } \\
\text { Bulan } \\
\text { (unit) }\end{array}$ & $\begin{array}{c}\text { Jumlah } \\
\text { Penjualan } \\
\text { per Tahun } \\
\text { (unit) }\end{array}$ & $\begin{array}{l}\text { Harga } \\
\text { Satuan }\end{array}$ & $\begin{array}{c}\text { Total } \\
\text { Pendapatan } \\
\text { per Bulan }\end{array}$ & $\begin{array}{l}\text { Total Pendapan per } \\
\text { Tahun }\end{array}$ \\
\hline Amigurumi : & & & & & & \\
\hline Lebah & 264 & 88 & 1056 & Rp 45.000 & Rp 3.960 .000 & Rp 47.520 .000 \\
\hline Burung Hantu & 264 & 88 & 1056 & Rp 55.000 & Rp 4.840 .000 & Rp 58.080 .000 \\
\hline Jerapah & 264 & 88 & 1056 & $\mathrm{Rp} 70.000$ & Rp 6.160 .000 & $\operatorname{Rp} 73.920 .000$ \\
\hline Bebek & 264 & 88 & 1056 & $\operatorname{Rp} 95.000$ & Rp 8.360 .000 & Rp 100.320 .000 \\
\hline Naga & 264 & 88 & 1056 & Rp 105.000 & $\operatorname{Rp} 9.240 .000$ & Rp 110.880 .000 \\
\hline Bunny & 264 & 4 & 48 & Rp 135.000 & Rp $\quad 540.000$ & $\begin{array}{ll}\mathrm{Rp} & 6.480 .000\end{array}$ \\
\hline Sleepy Doll & 264 & 4 & 48 & Rp 175.000 & $\begin{array}{ll}\mathrm{Rp} & 700.000\end{array}$ & Rp 8.400 .000 \\
\hline Kucing & 264 & 4 & 48 & Rp 200.000 & Rp $\quad 800.000$ & Rp $\quad 9.600 .000$ \\
\hline Total & 264 & 452 & 5424 & & Rp 34.600.000 & Rp 415.200.000 \\
\hline
\end{tabular}

Sumber : data diolah

Berdasarkan pada tabel 4 dapat dilihat proyeksi target penjualan M's Crochet pada tahun 2018 sebesar Rp415.200.000,00 dengan estimasi hari kerja 264 hari. Hari kerja di dapatkan dari 365 hari di kurangi dengan hari minggu sebanyak 52 hari dan hari besar lainnya. Penulis mengasumsikan bahwa dalam sebulan
M's Crochet mampu menghasilkan 452 unit amigurumi. Banyaknya jumlah amigurumi yang terjual disesuaikan dengan jumlah SDM sebanyak 4 orang. Proyeksi penjualan ini tidak bersifat konstan karena pertumbuhan ekonomi yang terjadi di Indonesia dan jumlah penawaran yang belum cukup untuk memenuhi seluruh permintaan yang diakibatkan dari terbatasnya Sumber Daya Manusia (SDM) M's Crochet.

Tabel 5. Proyeksi Laba

\begin{tabular}{|lccc|}
\hline \multicolumn{1}{c}{$\begin{array}{c}\text { Proyeksi Laba } \\
\text { M's Crochet }\end{array}$} & & \\
& 2018 & & \\
Pendapatan & & Rp & 415.200 .000 \\
Harga Pokok Penjualan & & Rp & $\mathbf{1 8 6 . 3 0 8 . 3 3 1}$ \\
Pendapatan Kotor & & Rp & $\mathbf{2 2 8 . 8 9 1 . 6 6 9}$ \\
Biaya Operasional & & & \\
\multicolumn{1}{|c|}{ Sewa Stand } & Rp 36.000 .000 & & \\
Total Biaya Operasional & & Rp & $\mathbf{( 3 6 . 0 0 0 . 0 0 0 )}$ \\
Laba Sebelum Pajak & & Rp & $\mathbf{1 9 2 . 8 9 1 . 6 6 9}$ \\
Pajak Penghasilan (1\%) & & Rp & $\mathbf{( 1 . 9 2 8 . 9 1 7 )}$ \\
Laba Bersih Setelah & & Rp & 190.962 .752 \\
Pajak & & & \\
\hline
\end{tabular}

Sumber : data diolah

Secara berturut-turut harga pokok penjualan dan biaya operasional M's Crochet sebesar 186.308.331,00 dan 36.000.000,00. Oleh karena itu, M's Crochet dapat memproyeksikan bahwa pada tahun 2018 akan memperoleh laba bersih sebesar Rp190.962.752,00. 
Tabel 6. Proyeksi Neraca Akhir

\begin{tabular}{|c|c|c|c|}
\hline Per & & & \\
\hline Aktiva & & & \\
\hline Aktiva Lancar & & & \\
\hline Kas & $\mathrm{Rp} 2$ & 8.510 .151 & \\
\hline Total Aktiva Lancar & & & Rp 248.510.151 \\
\hline Aktiva Tetap & & & \\
\hline Box Benang & $\mathrm{Rp}$ & 125.500 & \\
\hline Akumulasi Depresiasi Box Benang & $\mathrm{Rp}$ & $(25.100)$ & \\
\hline Box Peralatan Rajut & $\mathrm{Rp}$ & 24.000 & \\
\hline Akumulasi Depresiasi Box Peralatan Rajut & $\mathrm{Rp}$ & $(4.800)$ & \\
\hline Gunting & $\mathrm{Rp}$ & 15.000 & \\
\hline Akumulasi Depresiasi Gunting & $\mathrm{Rp}$ & $(3.000)$ & \\
\hline Hakpen & $\mathrm{Rp}$ & 61.500 & \\
\hline Akumulasi Depresiasi Hakpen & $\mathrm{Rp}$ & $(12.300)$ & \\
\hline Stich Marker & $\mathrm{Rp}$ & 4.000 & \\
\hline Akumulasi Depresiasi Stich Marker & $\mathrm{Rp}$ & $(4.000)$ & \\
\hline Jarum Tapestry & $\mathrm{Rp}$ & 6.000 & \\
\hline Akumulasi Depresiasi Jarum Tapestry & $\mathrm{Rp}$ & $(6.000)$ & \\
\hline Total Aktiva Tetap & & & 180.800 \\
\hline Total Aktiva & & & Rp 248.690.951 \\
\hline Kewajiban dan Modal Pemilik & & & \\
\hline Modal Pemilik (Awal) & $\mathrm{Rp}$ & 55.799 .283 & \\
\hline Laba tahun 2018 & $\mathrm{Rp}$ & 90.962 .752 & \\
\hline Utang Pajak & $\mathrm{Rp}$ & 1.928 .917 & \\
\hline Total Kewajiban dan Modal Pemilik & & & Rp 248.690.951 \\
\hline
\end{tabular}

Sumber : data diolah

Pada neraca akhir, aktiva tetap M's Crochet mengalami depresiasi sebesar Rp180.800,00 yang menyebabkan total aktiva $M$ 's Crochet sebesar

Rp248.690.951,00. Total kewajiban dan modal pemilik bisnis M's Crochet sama pada akhir tahun 2018 yaitu sebesar Rp248.690.951,00.
Pada neraca akhir tahun ini, M's Crochet mengasumsikan bahwa pajak belum dibayarkan sehingga utang pajak dimasukan pada bagian kewajiban dan modal pemilik. 
FRANCISCA HERMAWAN, PETRUS PIUS SALAMIN, MEILIANA

Analisis SWOT, Bisnis Model Kanvas, Dan Kelayakan Keuangan Studi Kasus Bisnis Amigurumi M's Crochet

Tabel 7. Perhitungan NPV dan Payback Period

\begin{tabular}{|c|c|c|c|c|c|c|c|c|}
\hline \multirow{4}{*}{$\begin{array}{l}\text { Laba Setelah Pajak } \\
\text { Penyusutan }\end{array}$} & \multicolumn{8}{|c|}{ Tahun } \\
\hline & $01 / 01 / 2018$ & $31 / 12 / 2018$ & \multicolumn{2}{|r|}{2019} & \multicolumn{2}{|r|}{2020} & \multirow{2}{*}{$\begin{array}{c}\mathbf{2 0 2 1} \\
\text { Rp 1.480.592.016 }\end{array}$} & \multirow{2}{*}{$\begin{array}{c}\mathbf{2 0 2 2} \\
\text { Rp } 1.938 .835 .190\end{array}$} \\
\hline & $\mathrm{Rp}$ & Rp 190.962 .752 & $\mathrm{Rp}$ & 694.501 .015 & $\mathrm{Rp}$ & 930.644 .122 & & \\
\hline & $\mathrm{Rp}$ & 55.200 & $\mathrm{Rp}$ & 61.200 & $\mathrm{Rp}$ & 61.200 & 61.200 & 101.200 \\
\hline Operasional Benefit & $\mathbf{R p}$ & Rp 191.017.952 & $\mathbf{R p}$ & 694.562 .215 & $\mathbf{R p}$ & 930.705 .322 & Rp 1.480.653.216 & Rp 1.938.936.390 \\
\hline Nilai Buku & $\mathrm{Rp}$ & $\mathrm{Rp}$ & $\mathrm{Rp}$ & - & $\mathrm{Rp}$ & - & $\mathrm{Rp}$ & 164.000 \\
\hline Investasi Aktiva Tetap & $\operatorname{Rp} \quad(236.000)$ & $\mathrm{Rp}$ & $\mathrm{Rp}$ & $(40.000)$ & $\mathrm{Rp}$ & $(10.000)$ & $(10.000)$ & $(210.000)$ \\
\hline Modal Kerja & Rp (55.563.283) & $\mathrm{Rp}$ & $\mathrm{Rp}$ & - & $\mathrm{Rp}$ & - & $\mathrm{Rp}$ & Rp $\quad 55.563 .283$ \\
\hline Net Benefit & Rp (55.799.283) & Rp 191.017.952 & $\mathbf{R p}$ & 694.522 .215 & & 930.695 .322 & Rp 1.480.643.216 & Rp 1.994.453.673 \\
\hline \multicolumn{2}{|c|}{$\begin{array}{l}\text { Discount Factor (6.5\%) per } 21 \text { Juli } 2016 \\
\text { yang diakses pada tanggal } 5 \text { Mei } 2017\end{array}$} & 0,93897 & & 0,88166 & & 0,82785 & 0,77732 & 0,72988 \\
\hline \multirow{2}{*}{\multicolumn{2}{|c|}{ Present Value }} & Rp 179.359.579 & $\mathbf{R p}$ & 612.331 .958 & $\mathbf{R p}$ & 770.475.277 & Rp 1.150.938.161 & Rp 1.455.713.515 \\
\hline & & \multicolumn{7}{|c|}{ Rp 4.168.818.490 } \\
\hline \multicolumn{2}{|l|}{ Investasi Awal } & \multirow{2}{*}{\multicolumn{7}{|c|}{$\begin{array}{l}\text { Rp }(55.799 .283) \\
\text { Rp 4.113.019.207 } \\
\end{array}$}} \\
\hline \multicolumn{2}{|c|}{ Net Present Value (NPV) } & & & & & & & \\
\hline \multicolumn{2}{|l|}{ Payback Period } & \multicolumn{7}{|c|}{3,5 bulan } \\
\hline
\end{tabular}

Sumber: data diolah : : data

Parameter NPV Hasil perhitungan NPV digunakan sebagai bahan pertimbangan pemilik dalam mengambil keputusan, apakah bisnis layak untuk dijalankan atau tidak. Jika nilai NPV $>0$, maka bisnis layak untuk dijalankan. Jika nilai NPV $<0$, maka tidak layak untk dijalankan. Sedangkan parameter payback periode menganalisis berapa lama suatu investasi akan kembali. Berdasarkan hasil perhitungan di atas, dapat diketahui PV selama 5 tahun sebesar Rp4.168.818.490,00 dengan investasi awal sebesar Rp55.799.283,00, sedangkan NPV (Net Present Value) yang diperoleh dalam bisnis ini lebih besar dari nol yaitu Rp4.113.019.207,00. Selain itu, jangka waktu pengembalian investasi awal yaitu selama 3,5 bulan. Oleh karena itu, bisnis amigurumi M's Crochet layak untuk dijalankan karena akan memberikan keuntungan bagi perusahaan.

\section{KESIMPULAN DAN SARAN}

Bisnis M's Crochet memiliki bentuk badan usaha perorangan dimana didirikan oleh satu orang pemilik. M's Crochet merupakan bisnis yang bergerak dalam bidang kerajinan yaitu boneka rajutan atau amigurumi. Nilai yang ditawarkan kepada konsumen yaitu menjual produk amigurumi yang berkualitas yang dimulai dari pemilihan bahan baku hingga proses pengiriman produk hingga sampai ke tangan konsumen. Target pasar yang dituju adalah masyarakat kalangan menengah ke atas, berusia 3 tahun ke atas, dan memiiki jiwa seni. $M$ 's Crochet juga memiliki rencana penjualan lima tahun ke depan yang bertumbuh sebesar 3.1 persen per tahunnya yang diasumsikan sama dengan pertumbuhan industri kreatif. 
Berdasarkan perhitungan laba setelah pajak selama 5 tahun kedepan, dapat disimpulkan bahwa nilai NPV M's Crochet sebesar Rp4.113.019.207,00 yang menunjukan nilai NPV M's Crochet $>0$ sehingga bisnis Amigurumi M's Crochet layak untuk dijalankan. Hasil dari perhitungan payback period M's Crochet menunjukkan bahwa jangka waktu yang dibutuhkan dalam pengembalian investasi awal yang dikeluarkan selama 3,5 bulan.

\section{DAFTAR PUSTAKA}

Ardana, K.I., Mujiati N., \& Utama, M.W. (2012). Manajemen Sumber Daya Manusia. (Edisi 1). Yogyakarta: Penerbit PT. Graha Ilmu.

Gambel, Peteraf, Thompson. (2015). Essential of Strategic Management: The Quest for Competitive Advantage. (4 ${ }^{\text {th }}$ ed.). New York: McGraw-Hill Education.

Heizer, J., \& Render, B. (2011). Operations Management. (10 ${ }^{\text {th }}$ ed.). One Lake Street, Upper Saddle River, New Jersey: Pearson Education Prentice Hall.

Howdy. (2012). Konsinyasi: Solusi Bagi Anda yang Tidak Memiliki Toko. Diakses tanggal 10 Februari 2017, http://www. zonabisnis.com

Ivancevich, J.M, Konopaske, R., \& Matteson, M.T. (2008). Perilaku dan Manajemen Organisasi. (Penerjemah: Gina Gania). Jakarta: Erlangga. (Buku asli diterbitkan 2007)

Kasali, R. (2007). Membidik Pasar Indonesia Segmentasi, Targeting, dan Positioning. Jakarta: PT.Gramedia Pustaka Utama.
Kotler, P., Bowen, J., \& Makens, J. (2002). Pemasaran Perhotelan dan Kepariwisataan Edisi Kedua. Jakarta: PT. Prenhallindo. (Buku asli diterbitkan 2002)

Kotler, P., \& Gary Armstrong. (2012). Principles of Marketing. (Global ed., 14 ${ }^{\text {th }}$ ed.). United States of America: Pearson Education.

Kotler, P., \& Keller, K. (2009). Manajemen Pemasaran. (13 ${ }^{\text {th }}$ ed.). (Penerjemah: Bob Sabran). Jakarta: Erlangga. (Buku asli diterbitkan 2008)

Margrit, A. (2016). Kontribusi Ekonomi Kreatif Mulai Aktif. Diakses tanggal 2 Februari 2017, http://koran.bisnis.com/ read/20161209/430/610663/kontribusiekonomi-kreatif-mulai-aktif-

Nilasari, S. (2014). Manajemen Strategi itu Gampang untuk Pemula dan Orang Awam. Jakarta: Dunia Cerdas.

Rangkuti, F. (2009). Analisis SWOT Teknik Membedah Kasus Bisnis. Jakarta: PT Gramedia Pustaka Umum.

Rangkuti, F. (2006), Analisis SWOT: Teknik Membedah Kasus Bisnis, Jakarta: PT Gramedia Pustaka Utama.

Ratna Heppy. (2013). Peluang Industri Boneka Indonesia Masih Terbuka Lebar. Diakses tanggal 17 Februari 2017. http:// www.antaranews.com/berita/379853/ peluang-industri-boneka-indonesiaterbuka-lebar

Robbins, S.P, \& Judge, T.A. (2008). Perilaku Organisasi. (Edisi 12). (Penerjemah: Diana Angelica, Ria Cahyani, \& Abdul 
FRANCISCA HERMAWAN, PETRUS PIUS SALAMIN, MEILIANA

Analisis SWOT, Bisnis Model Kanvas, Dan Kelayakan Keuangan Studi Kasus Bisnis Amigurumi M's Crochet

Rosyid). Jakarta: Salemba Empat. (Buku asli diterbitkan 2007).

Robbins, S.P., \& Coulter, M. (2009). Management. $\left(10^{\text {th }}\right.$ ed.). Upper Saddle River, New Jersey: Pearson Education Prentice Hall.

Simamora, B. (2003). Memenangkan Pasar dengan Pemasaran Efektif dan Profitabel. Jakarta: Gramedia Pustaka Utama.

Susanto, A.B., Wijarnako, H., Susanto, P., \& Mertosono, S. (2007). The Jakarta Consulting Group on Family Business. Jakarta: Publishing Division The Jakarta Consulting Group.
UU Nomor 3 Tahun 2014. (2014). UndangUndang No. 3 Tahun 2014 tentang Perindustrian. Jakarta: Kementerian Sekretariat Negara Republik Indonesia.

Yuliani, R. (2013). Apa yang dimaksud dengan Amigurumi?. Diakses tanggal 2 Februari 2017. http://belajarcaramerajut.com/ apa-yang-dimaksud-amigurumi.html 